\title{
EXAMINING MEDIATORS OF STRUCTURAL ASSURANCE CONSTRUCTS IN BUSINESS-TO-CONSUMER E-COMMERCE
}

\author{
Wei Sha Pittsburg State University wsha@pittstate.edu
}

\begin{abstract}
This study examines the influence of different types of structural assurance on consumer purchasing intentions in business-to-consumer (B2C) electronic commerce. Prior research findings regarding how different types of structural assurance impact consumer purchasing intentions has been limited. Based on the institution-based trust theory, perceived trust theory and the psychological contract theory, this study proposes that perceived vendor guarantee and perceived seals of approval would have positive influence on consumer intentions through psychological contract and perceived trust. Results of this study confirmed the significance of perceived vendor guarantee and perceived seals of approval and the importance of perceived trust in the nomological network.
\end{abstract}

Keywords: Structural assurance, psychological contract, perceived trust, purchasing intention

\section{INTRODUCTION}

The US Census Bureau estimated that online retail sales were about $\$ 136.4$ billion, which only accounted for 2.9 percent of total retail sales in 2007 [27]. This amount is far less than business analysts had hoped business-to-consumer (B2C) e-commerce would reach since its inception. For example, Forester Research predicted in 2000 that B2C ecommerce would reach $\$ 3$ trillion by 2003 [18]. Information system researchers found that one possible reason could be consumers' lack confidence about the trustworthiness of web vendors. Online consumer trust can be separated into two components: perceived trust (a web vendor's perceived specific trustworthy attributes, such as ability, integrity and benevolence), which can be formulated based on institutional structures and trusting intentions (consumers' willingness to depend on the web vendor) [13].

Institutional structures consist of different types of formal structures such as third party recognitions, warranties, guarantees and public key infrastructures in $\mathrm{B} 2 \mathrm{C}$ e-commerce. The effect of these formal structures is structural assurance, which is defined as the degree to which consumers believe that various formal structural procedures are in place to protect their interests and well-being [13]. Since existing empirical results show inconsistent findings about the influence of SA on consumer trust [8, 13], the underlining mechanism of the influence of SA need to further explored. Structural assurance is composed of customers' beliefs about protections from different assurance structures. Therefore, it might be possible that different types of assurance structures may have unique influences on consumers' intentions. If so, what are these types of structures? How are these types of structures related to online consumer purchasing intentions? This research concentrates on two institutional structures under a vendor's direct control, i.e. vendor guarantees and seals of approval.

This paper answers the research calls to further investigate the nature of structural assurance $[13,16$, 23]. This investigation is particularly important to web vendors because they can implement strategies to incorporate assurance structures into their website design to influence online consumer intentions. The rest of the paper is organized as follows: first, current research results about the influence of structural assurance on online consumer intentions are reviewed; second, a research model is proposed based on the institution-based trust mechanisms theory, perceived trust theory and the psychological contract theory; third, the research method and results are presented; and fourth, potential contributions and limitations are presented.

\section{MOTIVATION}

Empirical research on the impact of structural assurance on online consumer intentions shows a wide spectrum of results. A review of studies which examined the assurance of website design features indicates that the influence of structural assurance on consumers' trusting beliefs and intentions can be strong [8]; weak [14, 25]; mixed [5, 10, 12]; or not significant [13, 24].

Furthermore, there are only a few studies which have examined the psychological process of how structural assurance can influence consumers' purchase intentions. Most researchers propose a direct relationship between structural assurance and criterion constructs, such as intention to purchase [2]; 
trusting beliefs $[8,12,16]$; trusting intentions [10]; or both trusting beliefs and intentions [14].

\section{TYPES OF STRUCTURAL ASSURANCE}

Zucker's (1986) institution-based trust theory which used the mid-1800s to the early-1900s as the context suggests that institutional structures can be used to build trust to expedite business transactions when familiarity is lacking. Four types of formal institutional structures were used to produce trust during that period. The first type was a company's internal "written rules and a formal hierarchy that produced trust between employers and employees" [27, p.55]. The second type was the service provided by professional certifications to assure trustworthiness when informal reputation is hard to assess. The third type was the service provided by service sectors, such as finance, insurance, real estate, legal service and governments, which "arose to bridge transactions between firms and between individuals and firms" [27, p.55]. The fourth type was the framework of regulation, legislation and specific rules regarding every transaction. These four types of formal structures facilitated the production of institution-based trust and American economic development when there was no easy indication of either reputation or individual characteristics.

The B2C e-commerce environment closely resembles the business environment in the mid-1800s to the early-1900s. In B2C e-commerce, about $75 \%$ of the dot-com companies fail in their first two years of existence [15]. Under these circumstances, building a stable, trusting relationship with a web vendor becomes very difficult. As transaction participants chose to rely on formal, institutional structures in the volatile, pre-1920 period, customers today may need to depend on the formal, institutional structures as their safety net to provide a sense of assurance when they shop online. Based on Zucker's institution-based trust theory, the institutional structures in B2C ecommerce can be separated into four types: 1) vendor specific guarantees, 2) seals of approval, 3) credit card guarantees, and 4) legal legislations. Credit card guarantees and legal legislations are usually out of web vendors' direct control, and therefore they have little means to manipulate these two institution structures to increase web traffic. On the other hand, vendor specific guarantees and seals of approval are under a web vendor's complete control and can be manipulated for business gains. Therefore, this research concentrates on vendor specific guarantees and seals of approval.

The effect of these formal structures on consumer online trust is conveyed through website design features [8]. Website designers can use customer service policies, third party certification seals, and advanced encryption technologies to relay structural assurance information to consumers[16, 17]. Since each customer may have unique perception of the effect of different structures, there may be different types of perceptions about these institutional structures. Web vendors often make promises like, ' $100 \%$ satisfaction guarantee,' monetary refund, quality products, protection of privacy, and accurate product information, etc. These promises could be salient to consumers, and may be the basis to form psychological mutual understanding between consumers and web vendors and influence consumers' intentions. Perceived vendor guarantee is defined as the degree to which a customer believes that a web vendor's own customer service policies will guarantee the protection of customer's interests and well being. This research proposes that these perceptions will have positive effect on customers' purchasing intentions toward an online vendor.

Hypothesis 1: Perceived vendor guarantee will have a positive effect on customers' purchasing intentions toward an online vendor.

A seal of approval can be granted by an independent accreditation authority after a close examination and verification of an applicant's business policies and practices. Accreditation provides indicators of professionalism, ability, reliability, reputation and product quality, and can foster person or firmspecific trust [27]. Seals of approval may be particularly helpful in providing validation of a web vendor's effort to protect customers' privacy and security [20]. Perceived seal of approval guarantee is defined as the degree to which a customer believes that seals of approval from accreditation agencies can protect the customer's interests and well being. This research proposes that these perceptions will have positive effect on customers' purchasing intentions toward an online vendor.

Hypothesis 2: Perceived seal of approval guarantee will have a positive effect on customers' purchasing intentions toward an online vendor.

This research further proposes that these perceptions could influence consumer intentions through two mediators, i.e., perceived trust and psychological contract.

\section{MEDIATORS OF STRUCTURAL ASSURANCE}

\section{Perceived Trust}

Web vendors may use website design features such as seals of approval and various promises to increase 
its perceived trust from their customers. Perceived trust is defined as a truster's specific beliefs about a trustee's "competence (ability of the trustee to do what the truster needs), benevolence (trustee caring and motivation to act in the truster's interests), and integrity (trustee honesty and promise keeping)" [13, p. 337]. These beliefs reflect the truster's salient, subjective assessments of the situation and the truster's interaction with the trustee [1]. Research has shown the positive relationship between behavioral intentions and perceived trust. Although it is not the focus of this research to reconfirm this relationship, the validation of a proven relationship could provide additional evidence of nomological validity for the model. When web vendors make salient, specific claims through policies and seals of approval about how they will protect customer interests, their customers may believe these vendors are trustworthy and in turn, would likely to purchase from these vendors. Therefore, this research proposes that perceived vendor-specific guarantee and perceived seal of approval guarantee could positively influence perceived trust, and perceived trust subsequently would increase a customer's likelihood to purchase from a web vendor.

Hypothesis 3: Perceived vendor-specific guarantee will have a positive effect on perceived trust.

Hypothesis 4: Perceived seal of approval guarantee will have a positive effect on perceived trust.

Hypothesis 5: A customer's perceived trust will have a positive effect on the customer's purchasing intentions toward a web vendor.

\section{Psychological Contract}

Psychological contract is defined as "an individual's belief in mutual obligations between that person and another party such as an employer (either a firm or another person)" [21]. The foundation of psychological contract is mutuality, which means one party of the exchange relationship believes that there is a mutual understanding regarding each other's responsibilities [22]. Online vendors frequently make promises like, "100\% satisfaction guarantee," full refund, quality products, protection of privacy, and correct product information, etc. These promises are frequently illustrated through design features on a vendors' website, such as customer services policies, seals of approval, and text information, etc. Once these promises become salient to consumers, a mutual understanding could be formed that consumers would believe that the online vendors should keep their promises if they purchase from those online vendors. Therefore, this research proposes that perceived vendor-specific guarantee and perceived seal of approval guarantee beliefs may have positive influence on psychological contract.

Hypothesis 6: Perceived vendor-specific guarantee will have a positive effect on psychological contract.

Hypothesis 7: Perceived seal of approval guarantee will have a positive effect on psychological contract.

The essence of psychological contract is the reciprocal understanding of the obligation between two parties. When there is such an understanding in place, it should have significant impact on a customer's beliefs about whether a web vendor would care about its customers' wellbeing by fulfilling its promises. Furthermore, in B2C ecommerce context, a customer's psychological contract may have significant influence on the customer's intention to purchase from a web vendor. A consumer would likely purchase from a web vendor if the consumer believes that the vendor would reciprocate the consumer's order by delivering the right product and services. A breach of psychological contract would likely reduce the customer's intention to purchase from the web vendor.

Hypothesis 8: A customer's psychological contract will have a positive effect on the customer's perceived trust toward a web vendor.

Hypothesis 9: A customer's psychological contract will have a positive effect on the customer's purchase intentions toward a web vendor.

See Figure 1 for a graphical depiction of the proposed model and hypotheses. 


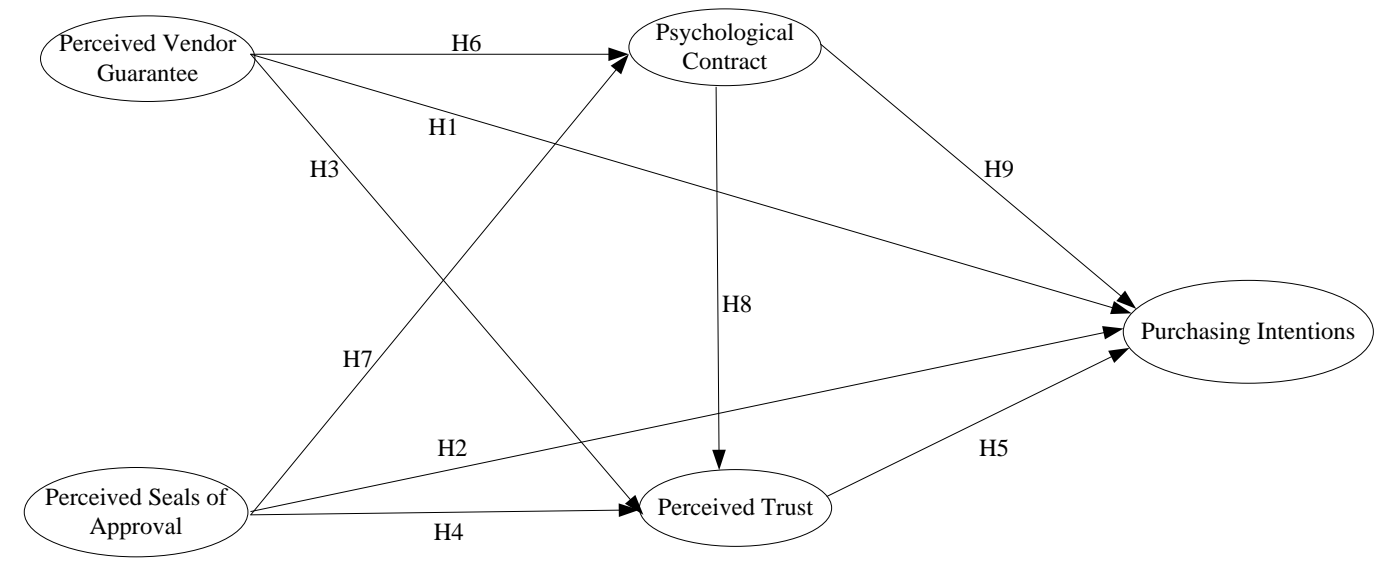

Figure 1 Proposed Research Model

\section{METHOD}

The purpose of the study is to validate the proposed structural assurance model through data collected from a survey study. Questionnaire items were adapted from validated instruments where possible, and all items are seven point Likert-type scales, anchored with 'strongly disagree' at 1 and 'strongly agree' at 7. Perceived seal of approval is measured by two items, "I believe that the Better Business Bureau undertook a thorough screening process before this website is allowed to use its seal," and "I believe that the Better Business Bureau makes substantial efforts to assess this website's true competencies." Perceived vendor guarantee is measured by two items, "I feel comfortable conducting business with this website because of its warranty policy," and "I feel safe conducting business with this website because of its return guarantees." Psychological contract is measured by three items, "this website will ship me the right product," "this website will treat its customer right," and "this website will provide the best quality product to me."Perceived trust is measured with four items, "this website provides good service," "this website is honest," "this store is predictable," and "this website is open and receptive to customer needs." Purchasing intention is measured with two items, "I trust this website completely," and "I intend to purchase from this website."

Questionnaires were completed by 203 undergraduate students enrolled at a Midwestern university. Using college students as participants is deemed appropriate because they are familiar with the online shopping environments [13, 14]. Students were instructed to visit a web store to select a gift which they would be interested in purchasing. At the end, students answered the questions based on their beliefs or opinions about the online store. Most of the respondents were between 20 to 23 years old and familiar with Internet and B2C ecommerce.

\section{RESULTS}

The analysis was conducted using structural equation modeling procedures. The convergent and discriminant validity of the proposed constructs are first examined. Once the constructs demonstrate appropriate validities and can differentiate themselves from each other, the proposed research model is tested for its predictive validity, i.e. whether the proposed model is indeed appropriate in predicting purchase intentions. The results showed that there are satisfactory evidence to support the existence of proposed constructs and the research model. Only two out of nine hypotheses were not supported. Detailed analysis and discussion of various structural equation modeling statistics can be found in the following sections.

\section{Convergent and Discriminant Validity}

The first step in validating the research model is to examine the convergent and discriminant validity of the constructs. Confirmatory factor analysis was conducted by using AMOS 6.0, a Structural Equation Modeling software package. The first indication of convergent and discriminant validity will be the overall fit of the proposed model to the data. Several fit indices can be used to assess the goodness of fit, such as the discrepancy ratio $(\chi 2 / \mathrm{df} ; \mathrm{df}=$ degrees of freedom), the adjusted goodness-of-fit (AGFI), the comparative fit index (CFI), the normative fit index (NFI), and the root mean square error of approximation (RMSEA). The discrepancy ratio should be smaller than 3 [11]. The AGFI should be higher than 0.8 [6]. The CFI and NFI should be 
greater than $0.9[13,6]$; and the RMSEA should be below or equal to 0.08 for a good fit and below 0.05 for an excellent fit [4]. The results show that the model has a satisfactory fit (discrepancy ratio, 1.72; AGFI, 0.89; CFI, 0.98; NFI, 0.96; RMSEA, 0.06). Average variance extracted (AVE) was used to further examine the fit of the model. The convergent validity can be established if AVE values of each construct exceed the criteria (0.5) set by Fornell and Larcker (1981). Discriminant validity can be shown if the AVE values are greater than the squared cross correlations among constructs. As shown in Table 1, the lowest AVE is 0.72 (purchasing) which far exceeds the 0.5 criteria, and is also just a little bit lower than the highest squared correlation between any pair of constructs $(0.72$ between perceived trust and psychological contract). The values of average variance extracted (AVEs) are displayed along the diagonal, and the correlations are displayed below the diagonal.

Table 1 AVE Values and Correlations of the Research Model

\begin{tabular}{lllllll} 
& Constructs & $\mathbf{1}$ & $\mathbf{2}$ & $\mathbf{3}$ & $\mathbf{4}$ & $\mathbf{5}$ \\
\hline 1 & Perceived Vendor Guarantee & $\mathbf{0 . 9 0}$ & & & & \\
2 & Perceived Seals of Approval & 0.42 & $\mathbf{0 . 8 5}$ & & & \\
3 & Psychological Contract & 0.59 & 0.44 & $\mathbf{0 . 7 2}$ & & \\
4 & Perceived Trust & 0.67 & 0.42 & 0.85 & $\mathbf{0 . 8 0}$ & \\
5 & Purchasing Intentions & 0.71 & 0.56 & 0.56 & 0.66 & $\mathbf{0 . 7 1}$ \\
& Mean & 4.86 & 4.73 & 5.25 & 4.77 & 4.35 \\
& Standard Deviation & 1.20 & 1.34 & 1.10 & 1.10 & 1.38
\end{tabular}

\section{Predictive Validity}

The predictive validity of the research model is assessed by examining how well the proposed constructs can explain the variance in the dependent variable, i.e. consumer purchasing intentions. Model fit statistics (discrepancy ratio, 1.72; AGFI, 0.89; CFI, 0.98; NFI, 0.96; RMSEA, 0.06) indicate that the model fits the data adequately. Hypothesis testing results (see Figure 2) show that while most of the hypotheses are supported, perceived seal of approval guarantee (H4) and psychological contract (H9) did not have significant influence on purchasing intentions. Significant amount of variance in perceived trust (77\%), psychological contract (39\%), and purchasing intentions $(64 \%)$ are explained by their predictors. Given that some of the correlations are higher than 0.70, multicollinearity was checked by calculating variance inflation factor scores (VIF) while regressing trusting intentions onto the types of structural assurance. The highest VIF is 2.89 , which indicates a very low level of multicollinearity [9].

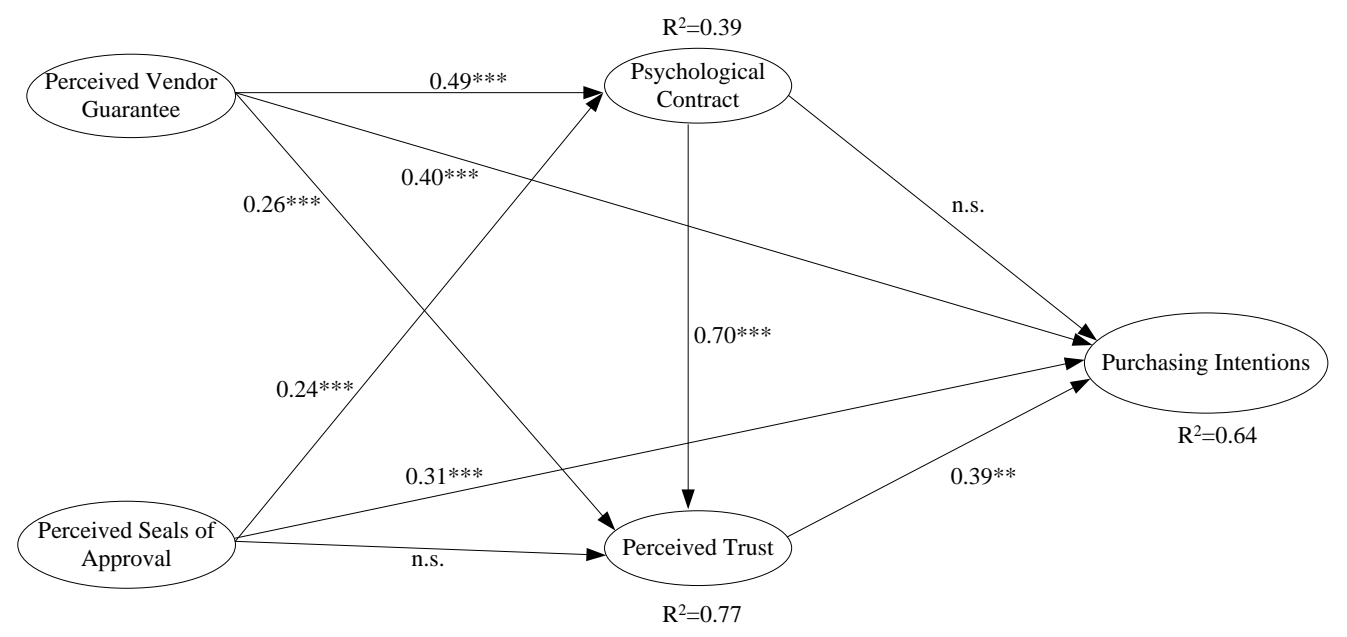

Figure 2 Research Model Results 


\section{DISCUSSION AND CONTRIBUTION}

This research adopts institution-base trust theory, psychological contract theory, and perceived trust theory to investigate different types of structural assurance (vendor guarantee and seals of approval) and their significant influence on customers' purchasing intentions in $\mathrm{B} 2 \mathrm{C}$ e-commerce context. Additionally, this research uses a survey study to examine the psychological process about how these two website design features impact consumers' online purchase intentions. The results validated the importance of vendor guarantees and seals of approval, and revealed their direct and mediated impact on purchasing intentions. Perceived trust plays a vital role since it explained additional variance in purchasing intentions above and beyond perceived vendor guarantees and perceived seals of approval. It is interesting to see that psychological contract does not directly influence purchasing intentions, and its influence is mediated through perceived trust. This certainly warrants further investigation. The success of e-commerce lies in how well web vendors can persuade customers to trust the vendors and subsequently make product purchases. The results of this study shows that web vendors can influence consumers' intentions through carefully crafted customer service policies and seals of approval. However, many web vendors tend to concentrate on other business practices, such as aesthetic interface design, the efficiency of order processing and effective inventory management. Service policies and seals of approval often receive less attention which leads to abbreviated/standard customer service policies or misplaced seals of approval. Customer service policies that are generic or limited in content may not be useful in building consumers' perception of web vendor quality. Therefore, web vendors need to focus more on improving their customer service policies and placement of seals of approval on their websites. Customized customer service policies and seals of approval should be easy to locate, enforceable and verifiable. Web vendors should abide by the guarantees they endorse; otherwise, a breach of trust could ensue. Psychological contract breach would be detrimental to a web vendor's image and bottom line. Another contribution is that this study answers the calls to further examine the nature of consumer trust mechanism in the $\mathrm{B} 2 \mathrm{C}$ e-commerce context through manipulations of a vendor's website attributes [13, 14].

\section{LIMITATION AND CONCLUSION}

The first limitation is that the analysis results are based on data collected from one survey study. While results from survey data can offer insights about a particular research situation, it is hard to derive causal relationships, to learn how things change over time or to draw general conclusions. Therefore, Additional data collection, either through a different survey or an experiment, is necessary to replicate the findings and to validate the causal relationships. The second limitation of the proposed research model is that this research does not investigate the effect of other contingency constructs such as trust propensity or risk propensity. A closer examination of the moderating influence of these constructs could provide a richer understanding of psychological contract. The third limitation is that this research does not investigate the possibility that the other important intervening constructs might be omitted from the model. However, this might not be a significant issue given that over $60 \%$ of the variance of purchasing intentions and perceived trust were explained. The predictors of psychological contract should be further explored given that only 39\% of variance in psychological contract were explained. The fourth limitation is that a convenient, student sample was used in data collection. Although this method is considered acceptable by some researchers, this student sample might not be representative of the online population in general. More representative samples are needed for future studies.

This paper answers explicit calls to further examine the nature of structural assurance and its relationship with other constructs such as perceived trust, psychological contract and purchasing intentions. This research confirmed the multi-facet characteristic of structural assurance and the intervening mechanism of the influence of structural assurance on consumer trust. The results of this research may provide another step toward better understanding of the nature and mechanisms of online institutional trust. Practitioners can also benefit from this study in terms of building customer trusting intentions through customer service policies and third party certifications. Customer service policies often receive less attention as evidenced by the fact that these policies are either limited in content or merely in standard form. Seals of approval are often used in an obscure fashion. This research may provide evidence that web vendors should better utilize institutional structures to improve online sales by increasing consumer trust and establishing psychological contract. 


\section{REFERENCES}

1. Ba, S. \& Pavlou, P. A. (2002). Evidence of the effect of trust building technology in electronic markets: price premiums and buyer behaviors. MIS Quarterly, 28(3), 243-268.

2. Belanger, F., Hiller, J. S. \& Smith, W. J. (2002). Trustworthiness in electronic commerce: the role of privacy, security, and site attributes, Journal of Strategic Information Systems, 11, 3-4, 245270.

3. Bentler, P. M. (1990). Comparative fit indexes in structural models. Psychological Bulletin, 107, 238-246.

4. Browne, M. W. \& Cudeck, R. (1993). Alternative ways of assessing model fit. K. A. Bollen, J. S. Long, eds. Testing Structural Equation Models. Newbury Park, CA: Sage.

5. Chellappa, R. K. \& Pavlou, P. A. (2002). Perceived information security, financial liability and consumer trust in electronic commerce transactions. Logistics Information Management, 15(5-6), 358-368.

6. Chin, W. W. \& Todd, P. A. (1995). On the use, usefulness, and ease of use of structural equation modeling in MIS research: a note of caution. MIS Quarterly, 19(2), 237-246.

7. Fornell, C. \& Larcker, D. F. (1981). Evaluating structural equation models with unobservable variables and measurement error. Journal of Marketing Research, 18(1), 39-50.

8. Gefen, D., Karahanna, E. \& Straub, D. W. (2003). Trust and TAM in online shopping: an integrated model, MIS Quarterly, 27, 51-90.

9. Hair, J. F. J., Anderson, R. E., Tatham, R. L. \& Black, W. C. (1998). Multivariate Data analysis with Readings. 5th Ed. Englewood Cliffs, NJ: Prentice Hall.

10. Kimery, K. M. \& McCord, M. (2002). Thirdparty assurances: mapping the road to trust in eretailing, Journal of Information Technology Theory and Application, 4(2), 63-82.

11. Kline, R. B. (1998). Principles and practice of structural equation modeling, New York, NY: The Guilford Press.

12. Kuan, K. \& Olson, J. (2002). Seal of approval and multidimensionality of perceived trustworthiness in online service adoption, The First Annual Workshop on HCI Research in MIS, Barcelona, Spain.

13. McKnight, D. H., Choudhury, V. \& Kacmar, C. (2002a). Developing and validating trust measures for e-commerce: an integrative typology, Information Systems Research, 13(3), 334-359.

14. McKnight, D. H., Choudhury, V. \& Kacmar, C. (2002b). The impact of initial consumer trust on intentions to transact with a web site: a trust building model, Journal of Strategic Information Systems, 11(3-4), 297-323.

15. Nataraj, S. \& Lee, J. (2002). Dot-com companies: are they all hype? S.A.M. Advanced Management Journal, 67, 10-14.

16. Pavlou, P. A. (2002). Institution-based trust in interorganizational exchange relationships: the role of online B2B marketplaces on trust formation, Journal of Strategic Information Systems, 11(3-4), 215-243.

17. Pavlou, P. A. \& Gefen, D. (2002). Building effective online marketplaces with institutionbased trust. Twenty-third International Conference on Information Systems, 667-675, Barcelona, Spain.

18. Phan, D.D \& Stata, N.M. (2002). E-business success at Intel: An organization ecology and resource dependence perspective. Industrial Management \& Data Systems, 102, 211-217.

19. Pillai, R., Schriesheim, C. A. \& Williams, E. S. (1999). Fairness perceptions and trust as mediators for transformational and transactional leadership: a two-sample study, Journal of Management, 25(6), 897-933.

20. Ranganathan, C. \& Ganapathy, S. (2002). Key dimensions of business-to-consumer web sites. Information \& Management, 39(6), 457-465.

21. Rousseau, D. M. \& Tijoriwala, S. A. (1998). Assessing psychological contracts: Issues, alternatives and measures, Journal of Organizational Behavior, 19, 679-695.

22. Rousseau, D. M. (2001). Schema, promise and mutuality: the building blocks of the psychological contract, Journal of Occupational and Organizational Psychology, 74(4), 511-541.

23. Shapiro, S. P. (1987). The social control of impersonal trust, American Journal of Sociology, 93(3), 623-658.

24. Shek, P. W., Sia, C. L. \& Lim, K. H. (2003). A preliminary assessment of different trust formation models: the effect of third party endorsements on online shopping, Proceedings of the $36^{\text {th }}$ Hawaii International Conference on System Sciences, Waikoloa, Hawaii.

25. Sultan, F., Urban, G. L., Shankar, V. \& Bart, I. Y. (2002). Determinants and role of trust in e- 
business: a large scale empirical study, Working Paper, Sloan School of Management, MIT, Cambridge.

26. US Census Bureau (2007). Quarterly retail ecommerce sales 4th quarter 2007. Retrieved July 15th, 2008, from http://www.census.gov/mrts/www/data/html/07Q 4.html.

27. Zucker, L. G. (1986). Production of trust: institutional sources of economic structure, 1840-1920, Research in Organizational Behavior, 8, 53-111. 